\title{
Eribulin mesylate as a microtubule inhibitor for treatment of patients with metastatic breast cancer
}

This article was published in the following Dove Press journal:

OncoTargets and Therapy

II November 201।

Number of times this article has been viewed

\section{Eva Muñoz-Couselo \\ José Pérez-García Javier Cortés}

Breast Cancer Unit, Vall d'Hebron Institute of Oncology, Vall d'Hebron University Hospital, Universitat Autònoma de Barcelona, Barcelona, Spain
Correspondence: Javier Cortés Department of Medical Oncology, Breast Cancer Unit,Vall d'Hebron University Hospital, Universitat Autònoma de Barcelona, Passeig Vall d'Hebron I19-129, 08035 Barcelona, Spain

Tel +349 32746085

Fax +34932746059

Email jacortes@vhebron.net

\begin{abstract}
Metastatic breast cancer (MBC) remains an incurable disease, with the goals of care aimed at maximizing the patient's duration and quality of life. Treatment options for MBC have become more efficacious and numerous. In addition to endocrine and chemotherapy agents, a number of targeted agents, including trastuzumab and bevacizumab, have further enhanced the landscape of therapeutic options. Eribulin mesylate (E7389) is a nontaxane microtubule dynamics inhibitor, and a structurally simplified synthetic analog of the natural marine product, halichondrin $\mathrm{B}$, with a novel mechanism of action that has shown antitumor activity in pretreated MBC. Eribulin has shown a manageable tolerability profile in Phase I-II clinical trials and an improvement in overall survival compared with treatment of physician's choice, without relevant toxicities in a recently published Phase III trial. This review will focus on eribulin as a new active agent for $\mathrm{MBC}$ and its role in the management of breast disease.
\end{abstract}

Keywords: metastatic breast cancer, eribulin mesylate, halichondrin B, tubulin-targeted agents

\section{Introduction}

Breast cancer is the most frequently diagnosed cancer worldwide and is also the second leading cause of death in women in the United States. ${ }^{1}$ The diagnosis of breast cancer metastases without a history of early-stage disease is rare, and approximately $20 \%$ of patients with early breast cancer develop distant metastases within 5 years of the initial diagnosis. ${ }^{1,2}$ Despite improvements in the numerous chemotherapeutic agents that have been developed for the treatment of metastatic breast cancer (MBC), there is no standard of care for patients who have experienced failure with initial treatment.

Optimal treatment for patients with $\mathrm{MBC}$ is dependent upon the risks and benefits associated with each treatment option, as well as with the stage of disease and performance status of each patient. Anthracyclines and taxanes are increasingly used as (neo) adjuvant therapy, and therefore the number of patients previously exposed to these agents by the time they develop MBC is rising. ${ }^{3}$ Current chemotherapeutic options for third-line or later treatment of MBC include the vinca alkaloids, ${ }^{4,5}$ gemcitabine, ${ }^{6-8}$ capecitabine, ${ }^{9-11}$ and ixabepilone, ${ }^{12-15}$ as well as new formulations of older drugs, such as liposomal anthracyclines ${ }^{16,17}$ and nanoparticle albumin-bound paclitaxel. ${ }^{18}$ Despite the large number of treatment options, the only approved monotherapies for late-line treatment of MBC are capecitabine and ixabepilone. Capecitabine has been approved in the United States and Europe for patients who are resistant to both taxane and anthracycline regimens, and for patients who experience taxane resistance or in whom anthracycline therapy is not indicated. On the other hand, ixabepilone is currently 
approved in the United States for use in combination with capecitabine in patients who do not respond to anthracyclines and taxanes, or as a single agent for patients who have failed on anthracyclines, taxanes, and capecitabine. ${ }^{19-22}$

The management of MBC is complex due to the absence of clear evidence-based guidelines for clinicians and the large number of clinical studies developed with several compounds. Moreover, because consecutive diverse therapeutic regimens are administered, there is an increased risk of different cumulative toxicities and development of drug resistance, limiting the current treatment options available. Despite these risks, overall survival in patients with $\mathrm{MBC}$ is increasing, and many patients with MBC still benefit from three or more lines of treatment. ${ }^{23}$ Moreover, additional treatment options are needed for heavily pretreated MBC patients. Eribulin mesylate has emerged as a new option in the late-line setting. This review will focus on the current data for this new drug.

\section{Antimicrotubule agents}

Microtubules are polymers made from proteins called $\alpha$ - and $\beta$-tubulin and are part of the cytoskeleton within the cytoplasm of the cell. In addition to providing structural support, microtubules take part in many other cellular processes. During the early stages of mitosis, many microtubules increase in length by attachment of more tubulin dimers to one end, and grow out from the spindle for long distances $(10 \mu \mathrm{m})$ into the cell, searching for an unattached chromosome. If none is found, the microtubule loses dimers and shrinks again. This expansion and retraction is repeated many times until eventually it meets and becomes chemically attached to a chromosome. When every chromosome has been captured by a microtubule, they are collected into the correct order and are then separated into two halves to divide the cell in two parts. ${ }^{24,25}$ With this division, apoptosis is induced.

The central role of antimicrotubular agents in the treatment of common epithelial cancers is further highlighted by their ability to induce remission in patients with classic drug-resistant epithelial cancers. ${ }^{26}$ Taxanes, vinca alkaloids, and epothilones are all microtubule-targeted agents which bind to tubulin with varying affinities and target different binding sites, with subsequent disruption of microtubule dynamics. This disruption occurs during mitosis with the induction of G2/M phase cell-cycle arrest that eventually leads to cell death by apoptosis. ${ }^{27,28}$ Among these agents, there are microtubule-stabilizing (paclitaxel, nab-paclitaxel, docetaxel, and the epothilones, eg, ixabepilone) and microtubule-destabilizing drugs (vinca alkaloids, eg, vincristine, vinblastine, and vinorelbine). ${ }^{29}$ However, current microtubule-targeted treatment is often limited by the development of drug resistance and common side effects, ${ }^{27,30}$ frequently based on high incidences of chronic peripheral sensory and motor neuropathy, with some studies reporting up to $20 \%-30 \%$ for patients experiencing grade $3 / 4$ neuropathic symptoms. ${ }^{31}$ Other common adverse events which impact upon quality of life in patients who receive these treatments are neutropenia and fatigue, and often result in dose modification or discontinuation of treatment. ${ }^{31,32}$

\section{Eribulin}

Eribulin mesylate (E7389) is a structurally simplified synthetic analog of the natural marine product, halichondrin $\mathrm{B}$, a nontaxane microtubule dynamics inhibitor extracted from the marine sponge Halichondria okadai (Figures 1 and 2) which inhibits structures called microtubules via a novel mechanism of action. Eribulin works by binding to microtubule polymerization, without affecting

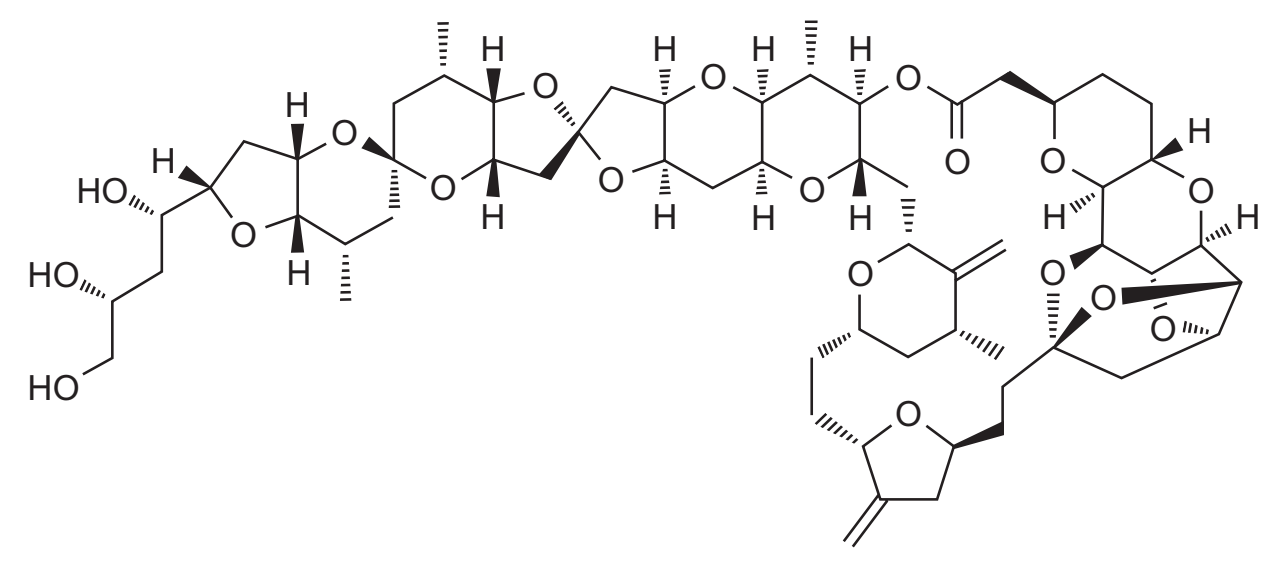

Figure I Molecular structure of halichondrin B. 


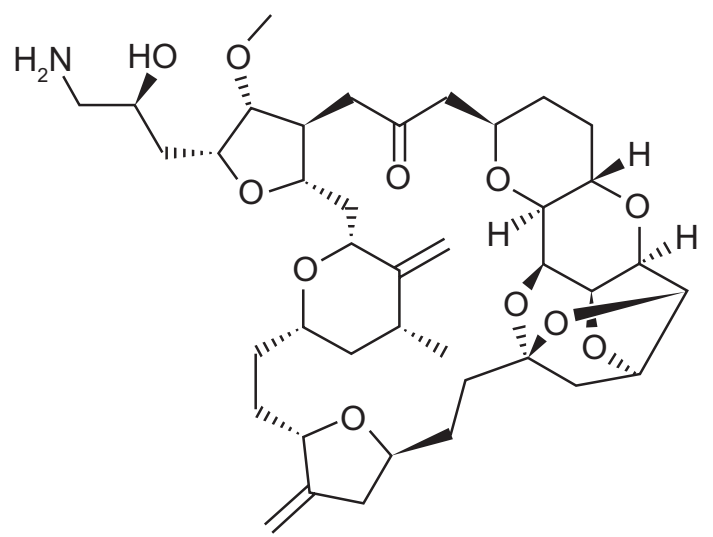

2-(3-Amino-2-hydroxypropyl)hexacosahydro3-methoxy- 26-methyl-20,27-bis(methylene) 11,15-18,21-24,28-triepoxy- 7,9-ethano-12,15methano- $9 H, 15 H$-furo(3,2-i)furo(2',3'-5,6) pyrano(4,3-b)(1,4)dioxacyclopentacosin-5-(4H)-one

Figure 2 Molecular structure of eribulin.

depolymerization, and with the additional sequestration of tubulin into nonfunctional aggregates. ${ }^{33}$ By inhibiting mitotic spindle formation, eribulin causes irreversible mitotic block, which leads to cell cycle arrest in the G2/M phase and apoptosis. ${ }^{34,35}$ Moreover, eribulin binds to a limited number of high affinity sites at the plus ends of the microtubules, and there is some evidence against its binding to interdimer interfaces in pre-existing polymers. This property distinguishes eribulin mechanistically from other antimicrotubule agents, such as paclitaxel, ixabepilone, and vinblastine. . $^{34,36,37}$

Eribulin, which retains the potency of halichondrin B against human cancer cell lines, has a mean terminal halflife of 40 hours, and minimal renal excretion have been shown in preclinical studies. ${ }^{38}$ Although it has been noted that this compound is metabolized by cytochrome $\mathrm{P} 450$ (CYP) 3A4, preclinical research established that it does not affect the metabolism of other therapeutic agents, such as diazepam, paclitaxel, midazolam, or tamoxifen, which are also metabolized by this system. ${ }^{39}$ Eribulin has shown antiproliferative effects against a broad range of human cancer cell lines, including breast, prostate, melanoma, and colorectal cancer ${ }^{40}$ has been associated with tumor regression and elimination in a variety of well established human tumor xenograft models,${ }^{41}$ and has demonstrated activity against paclitaxel-resistant cell lines, including those with mutations in $\beta$-tubulin..$^{36,42}$

Based on its novel mechanism of action, which is distinct from that of other known classes of tubulin-targeted agents, and its encouraging preclinical activity, eribulin was selected for evaluation in clinical trials. A comparison between eribulin and other antimicrotubule inhibitors is made in Table 1.

\section{Clinical efficacy and activity Phase I trials}

Four Phase I clinical trials have evaluated eribulin mesylate in various dose regimens in patients with different types of advanced solid tumors. ${ }^{38,43-45}$ Briefly, in the weekly regimen studies, the maximum tolerated dose of eribulin was reported to be $1.4 \mathrm{mg} / \mathrm{m}^{2}$ and $1 \mathrm{mg} / \mathrm{m}^{2}$. Eribulin was administered on days 1 , 8 , and 15 of a 28 -day cycle. ${ }^{44,45}$ On the other hand, a maximum tolerated dose of $2 \mathrm{mg} / \mathrm{m}^{2}$ was established on day 1 of a 21 -day cycle schedule, and finally, dosing on days 1 and 8 of a 21-day cycle led to a maximum tolerated dose of $1.4 \mathrm{mg} / \mathrm{m}^{2} .38,43$

Interestingly, some activity was observed in these trials. In the study by Goel et al, a partial response was observed in one patient $(3.1 \%)$ and stable disease was observed in

Table I Comparison between eribulin and other antimicrotubule agents active in $\mathrm{MBC}$

\begin{tabular}{|c|c|c|}
\hline Compound & Mechanism of action & Efficacy in MBC \\
\hline Paclitaxel & $\begin{array}{l}\text { Enhances polymerization } \\
\text { of tubulin and interacts directly } \\
\text { with microtubules, stabilizing } \\
\text { them against depolymerization }\end{array}$ & $\begin{array}{l}\text { RR, } 40 \%-58 \% \\
\text { PFS, } 9 \text { months } \\
\text { OS, } 24 \text { months }\end{array}$ \\
\hline Docetaxel & $\begin{array}{l}\text { Promotes suppression of } \\
\text { microtubule dynamics during } \\
\text { the assembly and disassembly } \\
\text { process }\end{array}$ & $\begin{array}{l}\text { RR, } 33 \% \\
\text { PFS, } 5.3 \text { months } \\
\text { OS }^{-}\end{array}$ \\
\hline Ixabepilone & $\begin{array}{l}\text { Binds to the } \alpha \beta \text {-tubulin } \\
\text { heterodimer subunit and } \\
\text { the rate of } \alpha \beta \text {-tubulin } \\
\text { dissociation decreases, and } \\
\text { has also been shown to induce } \\
\text { tubulin polymerization into } \\
\text { microtubules without the } \\
\text { presence of GTP }\end{array}$ & $\begin{array}{l}\text { RR, } 11.5 \% \\
\text { PFS, } 5.6 \text { months } \\
\text { OS, } 8.6 \text { months }\end{array}$ \\
\hline Vinorelbine & $\begin{array}{l}\text { Inhibits mitosis at metaphase } \\
\text { through its interaction with } \\
\text { tubulin and interferes with: } \\
\text { amino acid, cyclic AMP, and } \\
\text { glutathione metabolism; } \\
\text { calmodulin-dependent Ca }{ }^{2+} \\
\text { transport ATPase activity; } \\
\text { cellular respiration; and nucleic } \\
\text { acid and lipid biosynthesis }\end{array}$ & $\begin{array}{l}\text { RR, } 28 \%-36 \% \\
\text { PFS, } 4.1 \text { months } \\
\text { OS, } 22.9 \text { months }\end{array}$ \\
\hline Eribulin & $\begin{array}{l}\text { Involves binding to a unique } \\
\text { microtubule polymerization, } \\
\text { without affecting } \\
\text { depolymerization, and with } \\
\text { additional sequestration of } \\
\text { tubulin into nonfunctional } \\
\text { aggregates }\end{array}$ & $\begin{array}{l}\text { RR, } 12 \% \\
\text { PFS, } 3.7 \text { months } \\
\text { OS, } 13.1 \text { months }\end{array}$ \\
\hline
\end{tabular}

Abbreviations: OS, overall survival; PFS, progression-free survival; RR, response rate. 
10 patients $(31.3 \%) .{ }^{44}$ Synold et al reported two partial responses (5.3\%) and 12 patients (31.6\%) experienced stable disease. ${ }^{45}$ In addition, 12 patients $(57.1 \%)$ showed stable disease in the study reported by Tan et al, ${ }^{38}$ and Minami et al reported three patients with a partial response (20\%) and four patients who achieved stable disease (26.7\%). ${ }^{43}$

The most commonly reported dose-limiting toxicity in all four Phase I trials for eribulin was neutropenia. Two dose-limiting toxicities were reported at $2.0 \mathrm{mg} / \mathrm{m}^{2}$ (grade III febrile neutropenia in one patient, and grade IV neutropenia in another patient). Other serious nonhematologic toxicities included hypoglycemia, hypophosphatemia, and fatigue. In the study by Goel et al, grade III fatigue was observed in one patient at $0.5 \mathrm{mg} / \mathrm{m}^{2}$ which led to the expansion of that cohort. At $1.4 \mathrm{mg} / \mathrm{m}^{2}$, three patients developed grade III/ IV neutropenia, which was considered to be a dose-limiting toxicity based on the protocol criteria; febrile neutropenia developed in all three patients at $4.0 \mathrm{mg} / \mathrm{m}^{2}$, and two developed neutropenia at $2.8 \mathrm{mg} / \mathrm{m}^{2}$, which contributed to doselimiting toxicity at these different doses. ${ }^{44}$ In the study by Minami et al, dose-limiting grade IV neutropenia occurred in two of 15 patients (at $1.4 \mathrm{mg} / \mathrm{m}^{2}$ and $2.0 \mathrm{mg} / \mathrm{m}^{2}$, respectively), and grade III neutropenia occurred in four of 15 patients on the same dosing regimens. ${ }^{43}$

A further Phase IB combination study of eribulin and carboplatin in patients with advanced solid tumors determined the maximum tolerated dose of eribulin to be $1.1 \mathrm{mg} / \mathrm{m}^{2}$ in combination with carboplatin (area under the curve $6 \mathrm{mg} / \mathrm{dL} /$ minute). The study reported a partial response in two patients (3.8\%) and one complete response (1.9\%). ${ }^{46}$ Encouraging tumor response data from these four Phase I trials led to the initiation of Phase II studies in breast cancer patients, as well as in other types of solid tumors.

\section{Phase II trials}

Three Phase II studies of eribulin in patients with advanced breast cancer or MBC have already been completed. Patients who participated in these trials had received extensive pretreatments with a median of three or four (range 1-11) prior chemotherapy regimens. ${ }^{47-49}$ The first study was published by Vahdat et $a l^{50}$ who investigated the efficacy and safety of eribulin in 87 evaluable patients with $\mathrm{MBC}$ who had received prior treatment with an anthracycline and taxanes. Based on the results of the previous Phase I study, ${ }^{45}$ eribulin mesylate $1.4 \mathrm{mg} / \mathrm{m}^{2}$ was initially administered as a $2-5$-minute intravenous infusion on days 1, 8, and 15 of a 28 -day cycle. However, many patients experienced severe neutropenia on day 15 of the cycle (66\% grade $3 / 4$ in a 28 -day cohort) and therefore the schedule was amended; eribulin mesylate was finally administered on days 1 and 8 of a 21-day cycle. In this study, eribulin demonstrated an objective response rate of $11.5 \%$ (95\% confidence interval [CI], 5.7-20.1, all partial responses) and had a clinical benefit rate (partial response + stable disease for at least 6 months) of $17.2 \%$ (95\% CI, 10.0-26.8). ${ }^{49}$ The median duration of response, median progression-free survival, and median overall survival were 171 days (5.6 months; range 1.4-11.9), 79 days (2.6 months; range 0.03-14.9), and 275 days (9.0 months; range $0.5-27.2$ ), respectively. ${ }^{49}$ The most common drug-related grade $3 / 4$ toxicities were neutropenia (64\%), leucopenia (18\%), and fatigue (5\%).

In the second Phase II study, reported by Cortes et al, the patient population was based on 269 patients with locally advanced disease or MBC who had received prior treatment with anthracyclines, taxanes, and capecitabine. The patients received eribulin mesylate $1.4 \mathrm{mg} / \mathrm{m}^{2}$ as a 2-5-minute intravenous infusion on days 1 and 8 of a 21 -day cycle. The primary endpoint of objective response rate by independent reviewer was 9.3\% (95\% CI, 6.1-13.4, all partial responses), the stable disease rate was $46.5 \%$, and the clinical benefit rate (complete response + partial response + stable disease for at least 6 months) was $17.1 \%$; the investigator-reported objective response rate for this study was $14.1 \%$ (95\% CI, 10.2-18.9). The median duration of response was 4.2 months, with median reported progression-free survival and overall survival times of 2.6 months and 10.4 months, respectively. The most common treatment-related grade $3 / 4$ toxicities were neutropenia (54\%), leucopenia (14\%), and asthenia/fatigue (10\%, no grade 4 reported). Grade 3 peripheral neuropathy occurred in $5.5 \%$ of patients (no grade 4 was reported). ${ }^{47}$

Finally, in the third Phase II trial, reported by Iwata et al, ${ }^{49}$ the safety and efficacy of eribulin was investigated in 81 Japanese patients with advanced breast cancer who had previously been treated with an anthracycline and a taxane. This population study was less heavily pretreated than in the other two Phase II studies, with a median of only three prior treatments compared with four for the previously discussed two studies. The study implemented the same dosing regimen and mode of administration as that of the study by Cortés et a ${ }^{51}$ due to the schedule amendment needed in the study of Vahdat et al. ${ }^{50}$ The objective response rate by independent reviewer was $21.3 \%$ (all partial responses; 95\% CI, 12.9-31.8) and the stable disease and clinical benefit rates were $37.5 \%$ and $27.5 \%$ (95\% CI, 12.9-31.8), respectively. The median duration of response was 119 days (95\% CI, 85-148 days), the progression-free survival was 112 days (95\% CI, 61-133 days), and overall survival was 331 days 
(95\% CI, 234, no upper limit determined due to shortage of events), respectively. ${ }^{48}$

In all three Phase II studies, eribulin showed a manageable tolerability profile, with most of the common drug-related adverse events being neutropenia, fatigue, alopecia, nausea, and anemia (Table 2). ${ }^{47-49}$ Eribulin was also associated with a low incidence of peripheral neuropathy overall and severe peripheral neuropathy, which was limited to grade 3 only. ${ }^{47-49}$

\section{Phase III trials}

Following the encouraging pharmacokinetic and pharmacodynamic results observed in the Phase I trials and the response rates without severe adverse events observed in the Phase II trials in patients with extensively pretreated locally advanced or MBC, a Phase III trial lead to the approval of eribulin in the United States for the treatment of MBC in patients who have received at least two previous chemotherapeutic regimens, including an anthracycline and a taxane. EMBRACE (Eisai Metastatic Breast Cancer Study Assessing Physician's Choice Versus E7389) randomized patients with locally recurrent disease or MBC previously treated with 2-5 prior chemotherapy regimens (including anthracyclines and taxanes) to eribulin or treatment of physicians' choice (TPC). ${ }^{50}$ Based on data obtained from the Phase II trials, eribulin mesylate was administered at a dose of $1.4 \mathrm{mg} / \mathrm{m}^{2}$ as a 2-5-minute intravenous infusion on days 1 and 8 of a 21-day cycle and compared with TPC, defined as a single-agent chemotherapy, hormonal therapy, or biological therapy approved for the treatment of cancer and administered according to local practice, radiotherapy, or symptomatic treatment alone. Treatment continued until disease progression, unacceptable toxic effects, a patient or physician request to discontinue, or serious protocol noncompliance. The primary endpoint of the study was to compare overall survival between the two treatment groups; secondary objectives were to compare progression-free survival, objective response rate, and duration of response.

Table 2 Summary of most common grade 3/4 treatment-related adverse events from Phase II studies of eribulin

\begin{tabular}{llll}
\hline $\begin{array}{l}\text { Adverse event } \\
\mathbf{n}(\%)\end{array}$ & $\begin{array}{l}\text { Vahdat et al } \\
(\mathbf{n}=103)\end{array}$ & $\begin{array}{l}\text { Cortes et al } \\
(\mathbf{n}=\mathbf{2 9})\end{array}$ & $\begin{array}{l}\text { Total } \\
(\mathbf{n}=\mathbf{3 9 4})\end{array}$ \\
\hline Fatigue & $5(5)^{*}$ & $29(10)^{*}$ & $34(9)$ \\
Alopecia & $\mathrm{N} / \mathrm{A}$ & $\mathrm{N} / \mathrm{A}$ & $\mathrm{N} / \mathrm{A}$ \\
Neutropenia & $66(64)$ & $157(54)$ & $223(56.6)$ \\
Febrile neutropenia & $4(4)$ & $19(5.5)$ & $20(5.1)$ \\
Nausea & $\mathrm{I}(1)^{*}$ & $6(2.1)^{*}$ & $7(1.7)$ \\
Anemia & $\mathrm{I}(\mathrm{I})^{*}$ & $6(2)$ & $7(1.7)$ \\
\hline
\end{tabular}

Note: *No grade 4.

Abbreviation: N/A, not available.
Of the patients who received TPC (254 of a total of 762 included in the study), 96\% received chemotherapy and $4 \%$ received hormonal therapy, with no patients receiving biological therapy or best supportive care. Baseline demographic characteristics were well balanced across the treatment groups, as shown in Table 3. Most of the patients included in the study were heavily pretreated with a median of four previous chemotherapy regimens. The median duration of eribulin treatment was 3.9 months, and 295 patients (59\%) received five or more eribulin cycles. The study reached its primary objective, with a statistically significant increase in overall survival (hazard ratio $0.81 ; 95 \% \mathrm{CI}, 0.66-0.99 ; P=0.004$ ) in the eribulin group (13.1 months) compared with TPC group (10.6 months).${ }^{51}$ Median progression-free survival was 3.7 and 2.2 months (hazard ratio $0.87 ; 95 \% \mathrm{CI}, 0.71-1.05 ; P=0.14$ ), for the eribulin and TPC groups, respectively. The objective response rate was $12 \%$ in the eribulin group and $5 \%$ in the TPC group $(P=0.005)$. Finally, median duration of response for eribulin was 4.2 months (95\% CI, 3.8-5.0) and for TPC was 6.7 months $(95 \% \mathrm{CI}, 6.7-7.0 ; P=0.159)$. Adverse events occurred in 497 (99\%) of 503 patients receiving eribulin and 230 (93\%) of 247 patients given TPC. Grade 3/4

Table 3 Patient baseline characteristics in EMBRACE

\begin{tabular}{|c|c|c|c|}
\hline & $\begin{array}{l}\text { Eribulin \% } \\
(n=508)\end{array}$ & $\begin{array}{l}\text { TPC \% } \\
(n=254)\end{array}$ & $\begin{array}{l}\text { Total } \% \\
(n=762)\end{array}$ \\
\hline Median age (range) & $55(28-85)$ & $56(27-81)$ & $55(27-85)$ \\
\hline \multicolumn{4}{|c|}{ ECOG performance status (\%) } \\
\hline $0-1$ & 91 & 91 & 91 \\
\hline 2 & 8 & 9 & 8 \\
\hline $\begin{array}{l}\text { Estrogen receptor- } \\
\text { positive (\%) }\end{array}$ & 66 & 67 & 67 \\
\hline $\begin{array}{l}\text { Progesterone receptor- } \\
\text { positive (\%) }\end{array}$ & 50 & 48 & 50 \\
\hline HER2 positive & 16 & 16 & 16 \\
\hline Previous radiotherapy & 83 & 77 & 81 \\
\hline Previous surgery & 86 & 85 & 86 \\
\hline \multicolumn{4}{|l|}{ Number of organs involved } \\
\hline$\leq 2$ & 51 & 46 & 49 \\
\hline$>2$ & 49 & 54 & 51 \\
\hline \multicolumn{4}{|c|}{ Number of previous chemotherapy regimens } \\
\hline$\leq 3$ & 49 & 45 & 48 \\
\hline$>3$ & 53 & 55 & 53 \\
\hline Median & $4(I-7)$ & $4(2-7)$ & $4(I-7)$ \\
\hline \multicolumn{4}{|l|}{ Previous treatment } \\
\hline Taxane & 99 & 99 & 99 \\
\hline Capecitabine & 73 & 74 & 73 \\
\hline Anthracycline & 99 & 98 & 99 \\
\hline Refractory to Taxanes & 81 & 80 & 81 \\
\hline Capecitabine & 67 & 69 & 68 \\
\hline Anthracycline & 56 & 61 & 58 \\
\hline
\end{tabular}

Abbreviations: ECOG, Eastern Cooperative Oncology Group; EMBRACE, Eisa Metastatic Breast Cancer Study Assessing Physician's Choice versus Eribulin; HER2. human epidermal growth factor receptor 2; TPC, treatment of physician's choice. 
adverse events associated with eribulin were asthenia/fatigue (8.2\% grade $3 ; 0.6 \%$ grade 4$)$, neutropenia, and peripheral neuropathy, demonstrating a manageable tolerability profile for this agent when given as monotherapy ${ }^{51}$ (Table 4). Globally, neutropenia was the most common clinical grade 3 or 4 adverse event with eribulin $(21.1 \%$ grade $3 ; 24.1 \%$ grade 4); neutropenia also occurred in the TPC subgroups treated with vinorelbine ( $30 \%$ grade $3 ; 10 \%$ grade 4$)$, taxanes (13\% grade $3 ; 16 \%$ grade 4 ), or gemcitabine (20\% grade $3 ; 7 \%$ grade 4$)$. It was managed with dose delays, dose reductions, and granulocyte colony-stimulating factor (given to $18 \%$ of patients in the eribulin group and $8 \%$ in the TPC group). The overall incidence of peripheral neuropathy on eribulin was $35 \%$ (7.8\% grade $3 ; 0.4 \%$ grade 4$)$, and was similar to that observed in the taxane subgroup ( $45 \%$ overall, $5 \%$ grade 3 , no grade 4). Moreover, it was the most common adverse event leading to discontinuation of eribulin in $5 \%$ of patients, but in those patients with grade 3 or 4 peripheral neuropathy who discontinued treatment, neuropathy improved to grade 2 or lower in later cycles after delays and dose reductions. ${ }^{50}$

Taken together, EMBRACE has shown a statistically significant improvement in its primary endpoint of overall survival by a median of 2.5 months with eribulin compared with TPC, and has also demonstrated a manageable tolerability profile in patients with heavily pretreated MBC. This survival benefit for eribulin over standard therapy in this setting is remarkable and contrasts with the failure of other agents to improve overall survival when added to chemotherapy in other clinical trials. Moreover, the design of EMBRACE clearly reflects real practice, with the second arm of the study based on TPC as the comparator, the possibility of which allows choice of best therapy based on a combination of patient-related and tumor-related characteristics.

A second Phase III study is underway to compare the efficacy and safety of eribulin mesylate $\left(1.4 \mathrm{mg} / \mathrm{m}^{2}\right.$ as a 2-5-minute intravenous infusion on days 1 and 8 of a 21-day cycle) with capecitabine. In this trial, 1100 patients have

Table 4 Main grade 3/4 toxicities of eribulin in EMBRACE

\begin{tabular}{lll}
\hline & Grade 3 & Grade 4 \\
\hline Hematological toxicity (\%) & & \\
Neutropenia & 21.1 & 41.1 \\
Leukopenia & 11.7 & 2.2 \\
Anemia & 1.8 & 0.2 \\
Febrile neutropenia & 3.0 & 1.2 \\
Fatigue & 8.2 & 0.6 \\
Peripheral neuropathy & 7.8 & 0.4 \\
Dyspnea & 3.6 & 0 \\
\hline
\end{tabular}

Abbreviation: EMBRACE, Eisai Metastatic Breast Cancer Study Assessing Physician's Choice versus Eribulin. been randomized to receive eribulin or oral capecitabine on a $2500 \mathrm{mg} / \mathrm{m}^{2} /$ day schedule in two divided doses on days $1-14$ of a 21-day cycle. ${ }^{52}$ This study has two primary endpoints, ie, progression-free survival and overall survival, and in contrast with EMBRACE, it contains important quality of life and pharmacokinetic correlates. It will also use the same eribulin dosing schedule as EMBRACE and will also focus on those patients with disease progression despite receiving anthracyclines and taxanes. However, this study has more restrictive inclusion criteria and patients are not permitted to have received capecitabine for more than two previous chemotherapeutic regimens for MBC. The study has already finished recruitment and is currently investigating the effect of these drugs in combination in less extensively treated patients with locally advanced or MBC who have received up to three prior chemotherapy regimens, including anthracyclines and taxanes. Moreover, this will be the first study to provide a full analysis of the impact of eribulin upon quality of life. ${ }^{52}$

\section{Conclusion}

Eribulin is a novel nontaxane microtubule dynamics inhibitor with a novel mechanism of action distinct from those of other tubulin-targeting agents. In Phase II and III trials, it has demonstrated therapeutic activity in patients with solid tumors, particularly in heavily pretreated patients with MBC. Moreover, in the Phase III EMBRACE study it was shown to prolong overall survival in heavily pretreated $\mathrm{MBC}$ patients who received eribulin as monotherapy with manageable toxicity and a modest incidence of neuropathy, which appears to be lower than with other microtubule agents. Overall, eribulin represents a promising new treatment option for single-agent chemotherapy in patients with locally advanced disease or MBC previously treated with an anthracycline and a taxane.

\section{Future perspectives}

$\mathrm{MBC}$ is generally an incurable disease, with survival ranging from months to several years depending on tumor and patient characteristics. A wide range of treatment choices have been developed and are currently available, but most of them have not demonstrated an impact on survival in patients with MBC. Although currently there is no clear standard of care for these patients, important but modest improvements in overall survival have been observed for women with MBC. For women with endocrine-responsive disease, hormonal therapy is the appropriate initial treatment of choice at the time of disease recurrence. However, initiation of systemic chemotherapy is appropriate for women with metastatic disease that is either hormone receptor-negative, refractory to endocrine therapy, 
or rapidly progressive, with important visceral involvement regardless of hormonal status. ${ }^{53}$ The addition of an anti-HER2 agent to chemotherapy for women with HER2-positive breast cancer represents a clear standard of care for this population, with an impact on survival in this group of patients. ${ }^{54}$ Eribulin represents a new option for patients with heavily pretreated $\mathrm{MBC}$ and, due to the results of the clinical trials, it is likely to be partnered with other chemotherapy agents, anti-HER2 agents, and other drugs targeting important biologic pathways.

Eribulin has also demonstrated efficacy in heavily pretreated patients with $\mathrm{MBC}$ and a statistically significant improvement in survival in this group of patients. This encouraging efficacy, coupled with a manageable tolerability profile, has led to its approval by the US Food and Drug Administration and the European Agency for the Evaluation of Medicinal Products for the treatment of MBC in patients who have previously received chemotherapy including an anthracycline and a taxane. In addition, there are clinical trials underway to assess the antitumor activity of eribulin in the preoperative setting and also the earlier use of eribulin in the course of metastatic disease. It is hoped that these studies will translate the important survival advantage seen in the heavily pretreated refractory setting of the EMBRACE study into corresponding benefits for those patients with early-stage breast cancer. Moreover, a randomized Phase II study is comparing neuropathy associated with eribulin and with ixabepilone, ${ }^{55}$ and there are other ongoing studies of eribulin in multiple types of solid tumors, with some data showing activity in urothelial cancer, prostate cancer, and sarcoma.

In summary, eribulin is the only drug that has shown a survival advantage in late lines of therapy for patients with metastatic breast cancer. The benefit that eribulin has shown as a single agent in this setting suggests that this drug could become a new standard of care for these patients. Future studies should explore whether survival with late lines of therapy are indicative of a more effective drug used earlier and in the (neo)adjuvant setting, and should look to establish the optimal use of eribulin.

\section{Disclosure}

The authors report no conflicts of interest in this work.

\section{References}

1. Jemal A, Siegel R, Xu J, Ward E. Cancer statistics. CA Cancer J Clin. 2010;60(5):277-300.

2. Arriagada R, Spielmann M, Koscielny S, et al. Patterns of failure in a randomized trial of adjuvant chemotherapy in postmenopausal patients with early breast cancer treated with tamoxifen. Ann Oncol. 2002;13(9): $1378-1386$
3. Rivera E. Management of metastatic breast cancer: monotherapy options for patients resistant to anthracyclines and taxanes. Am J Clin Oncol. 2010;33(2):176-185.

4. Fumoleau P, Delgado FM, Delozier T, et al. Phase II trial of weekly intravenous vinorelbine in first-line advanced breast cancer chemotherapy. J Clin Oncol. 1993;11(7):1245-1252.

5. Livingston RB, Ellis GK, Gralow JR, et al. Dose-intensive vinorelbine with concurrent granulocyte colony-stimulating factor support in paclitaxel-refractory metastatic breast cancer. J Clin Oncol. 1997; 15(4):1395-1400.

6. Smorenburg $\mathrm{CH}$, Bontenbal M, Seynaeve C, et al. Phase II study of weekly gemcitabine in patients with metastatic breast cancer relapsing or failing both an anthracycline and a taxane. Breast Cancer Res Treat. 2001;66(1):83-87.

7. Blackstein M, Vogel CL, Ambinder R, et al. Gemcitabine as firstline therapy in patients with metastatic breast cancer: a phase II trial. Oncology. 2002;62(1):2-8.

8. Modi S, Currie VE, Seidman AD, et al. A phase II trial of gemcitabine in patients with metastatic breast cancer previously treated with an anthracycline and taxane. Clin Breast Cancer. 2005;6(1):55-60.

9. Blum JL, Jones SE, Buzdar AU, et al. Multicenter phase II study of capecitabine in paclitaxel-refractory metastatic breast cancer. $J$ Clin Oncol. 1999;17(2):485-493.

10. Blum JL, Dieras V, Lo Russo PM, et al. Multicenter, Phase II study of capecitabine in taxane-pretreated metastatic breast carcinoma patients. Cancer. 2001;92(7):1759-1768.

11. Oshaughnessy JA, Blum J, Moiseyenko V, et al. Randomized, openlabel, phase II trial of oral capecitabine (Xeloda) vs a reference arm of intravenous CMF (cyclophosphamide, methotrexate and 5-fluorouracil) as first-line therapy for advanced/metastatic breast cancer. Ann Oncol. 2001;12(9):1247-1254.

12. Low JA, Wedam DB, Lee JJ, et al. Phase II clinical trial of ixabepilone (BMS-247550), an epothilone B analog, in metastatic and locally advanced breast cancer. J Clin Oncol. 2005;23(12):2726-2734.

13. Thomas E, Tabernero J, Fornier M, et al. Phase II clinical trial of ixabepilone (BMS-247550), an epothilone B analog, in patients with taxane-resistant metastatic breast cancer. J Clin Oncol. 2007;25(23):3399-3406.

14. Perez EA, Lerzo G, Pivot X, et al. Efficacy and safety of ixabepilone (BMS-247550) in a phase II study of patients with advanced breast cancer resistant to an anthracycline, a taxane, and capecitabine. J Clin Oncol. 2007;25(23):3407-3414.

15. Roche H, Yelle L, Cognetti F, et al. Phase II clinical trial of ixabepilone (BMS-247550), an epothilone B analog, as first-line therapy in patients with metastatic breast cancer previously treated with anthracycline chemotherapy. J Clin Oncol. 2007;25(23):3415-3420.

16. Batist G, Harris L, Azarnia N, Lee LW, Daza-Ramirex P. Improved anti-tumor response rate with decreased cardiotoxicity of non-pegylated liposomal doxorubicin compared with conventional doxorubicin in first-line treatment of metastatic breast cancer in patients who had received prior adjuvant doxorubicin: results of a retrospective analysis. Anticancer Drugs. 2006;17(5):587-595.

17. Al-Batran SE, Guntner M, Pauligk C, et al. Anthracycline rechallenge using pegylated liposomal doxorubicin in patients with metastatic breast cancer: a pooled analysis using individual data from four prospective trials. Br J Cancer. 2010;103(10):1518-1523.

18. Gradishar WJ, Tjulandin S, Davidson N, et al. Phase III trial of nanoparticle albumin-bound paclitaxel compared with polyethylated castor oil-based paclitaxel in women with breast cancer. $J$ Clin Oncol. 2005;23(31):7794-7803.

19. Cardoso F, Senkus-Konefka E, Fallowfield L, Costa A, Castiglione M; ESMO Guidelines Working Group. Locally recurrent or metastatic breast cancer: ESMO Clinical Practice Guidelines for diagnosis, treatment and follow-up. Ann Oncol. 2010;21 Suppl 5:v15-v19.

20. Ho J, Zhang L, Todorova L, Whillans F, Corey-Lisle P, Yuan Y. Budget impact analysis of ixabepilone used according to FDA approved labeling in treatment-resistant metastatic breast cancer. J Manag Care Pharm. 2009;15(6):467-475. 
21. Sparano JA, Vrdoljak E, Rixe O, et al. Randomized phase III trial of ixabepilone plus capecitabine versus capecitabine in patients with metastatic breast cancer previously treated with an anthracycline and a taxane. J Clin Oncol. 2010;28(20):3256-3263.

22. Thomas ES, Gomez HL, Li RK, et al. Ixabepilone plus capecitabine for metastatic breast cancer progressing after anthracycline and taxane treatment. J Clin Oncol. 2007;25(33):5210-5217.

23. Dufresne A, Pivot X, Tournigand C, et al. Impact of chemotherapy beyond the first line in patients with metastatic breast cancer. Breast Cancer Res Treat. 2008;107(2):275-279.

24. Jordan MA, Kamath K, Manna T, et al. The primary antimitotic mechanism of action of the synthetic halichondrin E7389 is suppression of microtubule growth. Mol Cancer Ther. 2005;4(7):1086-1095.

25. Jordan MA, Walker D, de Arruda M, et al. Suppression of microtubule dynamics by binding of cemadotin to tubulin: possible mechanism for its antitumor action. Biochemistry. 1998;37(50):17571-17578.

26. Miller RK, Matheos D, Rose MD. The cortical localization of the microtubule orientation protein, Kar9p, is dependent upon actin and proteins required for polarization. J Cell Biol. 1999;144(5):963-975.

27. Pasquier E, Kavallaris M. Microtubules: a dynamic target in cancer therapy. IUBMB Life. 2008;60(3):165-170.

28. Jordan MA, Kamath K. How do microtubule-targeted drugs work? An overview. Curr Cancer Drug Targets. 2007;7(8):730-742.

29. Higa GM. The microtubule as a breast cancer target. Breast Cancer. 2011;18(2):103-119.

30. Kavallaris M, Annereau JP, Barret JM. Potential mechanisms of resistance to microtubule inhibitors. Semin Oncol. 2008;35(3 Suppl 3):S22-S27.

31. Swain SM, Arezzo JC. Neuropathy associated with microtubule inhibitors: diagnosis, incidence, and management. Clin Adv Hematol Oncol. 2008;6(6):455-467.

32. Lee JJ, Swain SM. Peripheral neuropathy induced by microtubulestabilizing agents. J Clin Oncol. 2006;24(10):1633-1642.

33. Jimeno A. Eribulin: rediscovering tubulin as an anticancer target. Clin Cancer Res. 2009;15(12):3903-3905.

34. Dabydeen DA, Burnett JC, Bai R, et al. Comparison of the activities of the truncated halichondrin B analog NSC 707389 (E7389) with those of the parent compound and a proposed binding site on tubulin. Mol Pharmacol. 2006;70(6):1866-1875.

35. Smith JA, Wilson J, Azarenko O, et al. Eribulin binds at microtubule ends to a single site on tubulin to suppress dynamic instability. Biochemistry. 2010;49(6):1331-1337.

36. Okouneva T, Azarenko O, Wilson L, et al. Inhibition of centromere dynamics by eribulin (E7389) during mitotic metaphase. Mol Cancer Ther. 2008;7(7):2003-2011.

37. Huyck TK, Gradishar W, Manuguid F, Kirkpatrick P. Eribulin mesylate. Nat rev Drug Discov. 2011;10(3):173-174.

38. Tan AR, Rubin EH, Walton DC, et al. Phase I study of eribulin mesylate administered once every 21 days in patients with advanced solid tumors. Clin Cancer Res. 2009;15(12):4213-4219.

39. Zhang ZY, King BM, Pelletier RD, Wong YN. Delineation of the interactions between the chemotherapeutic agent eribulin mesylate (E7389) and human CYP3A4. Cancer Chemother Pharmacol. 2008;62(4):707-716.
40. Hamel E. Natural products which interact with tubulin in the vinca domain: maytansine, rhizoxin, phomopsin A, dolastatins 10 and 15 and halichondrin B. Pharmacol Ther. 1992;55(1):31-51.

41. Towle MJ, Salvato KA, Budrow J, et al. In vitro and in vivo anticancer activities of synthetic macrocyclic ketone analogues of halichondrin B. Cancer Res. 2001;61(3):1013-1021.

42. Newman S. Eribulin, a simplified ketone analog of the tubulin inhibitor halichondrin B, for the potential treatment of cancer. Curr Opin Investig Drugs. 2007;8(12):1057-1066.

43. Minami HM, Nagai S, Mukai H, Namiki M. A phase I study of eribulin mesylate (E7389) in patients with refractory cancers. Eur J Cancer. 2008; Suppl 6(140): abstract 446.

44. Goel S, Mita AC, Mita M, et al. A phase I study of eribulin mesylate (E7389), a mechanistically novel inhibitor of microtubule dynamics, in patients with advanced solid malignancies. Clin Cancer Res. 2009;15(12):4207-4212.

45. Synold TW, Morgan RJ, Newman EM, et al. A phase I pharmacokinetic and target validation study of the novel anti-tubulin agent E7389: a California Cancer consortium trial. J Clin Oncol. 2005;23(16S):3036.

46. Swami U, Petrylak DP, Raftopoulos H, et al. Phase IB study of eribuin mesylate in combination with carboplatin inpatients with advanced solid tumors. J Clin Oncol. 2010;28:15s.

47. Cortes J, Vahdat L, Blum JL, et al. Phase II study of the halichondrin B analog eribulin mesylate in patients with locally advanced or metastatic breast cancer previously treated with an anthracycline, a taxane, and capecitabine. J Clin Oncol. 2010;28(25):3922-3928.

48. Iwata $\mathrm{H}$, Aogi $\mathrm{K}$, Masuda $\mathrm{N}$, et al. Efficacy and safety of eribulin in Japanese patients (pts) with advanced breast cancer. J Clin Oncol. 2010;28(15):1081.

49. Vahdat LT, Pruitt B, Fabian CJ, et al. Phase II study of eribulin mesylate, a halichondrin B analog, in patients with metastatic breast cancer previously treated with an anthracycline and a taxane. J Clin Oncol. 2009;27(18):2954-2961.

50. Cortes J, O'Shaughnessy J, Loesch D, et al. Eribulin monotherapy versus treatment of physician's choice in patients with metastatic breast cancer (EMBRACE): a phase 3 open-label randomised study. Lancet. 2011;377(9769):914-923.

51. Twelves C, Loesch D, Blum JL, et al. A phase III study (EMBRACE) of eribulin mesylate versus treatment of physicians' choice in patients with locally recurrent or metastatic breast cancer previously treated with an anthracycline and a taxane. J Clin Oncol. 2010;28:18s.

52. Twelves C, Cortes J, Vahdat LT, et al. Phase III trials of eribulin mesylate (E7389) in extensively pretreated patients with locally recurrent or metastatic breast cancer. Clin Breast Cancer. 2010;10(2):160-163.

53. Morris PG, McArthur HL, Hudis CA. Therapeutic options for metastatic breast cancer. Expert Opin Pharmacother. 2009;10(6):967-981.

54. Murphy CG, Fornier M. HER2-positive breast cancer: beyond trastuzumab. Oncology (Williston Park). 2010;24(5):410-415.

55. Study Comparig Eribulin Mesylate and Ixabepilone in Causing or Exacerbating Neuropathy in Patients With Advanced Breast Cancer. NCT00879086. Available from: http://clinicaltrials.gov/ct2/show/ NCT00879086. Accessed October 11, 2010.
OncoTargets and Therapy

\section{Publish your work in this journal}

OncoTargets and Therapy is an international, peer-reviewed, open access journal focusing on the pathological basis of all cancers, potential targets for therapy and treatment protocols employed to improve the management of cancer patients. The journal also focuses on the impact of management programs and new therapeutic agents and protocols on

\section{Dovepress}

patient perspectives such as quality of life, adherence and satisfaction The manuscript management system is completely online and includes a very quick and fair peer-review system, which is all easy to use. Visit http://www.dovepress.com/testimonials.php to read real quotes from published authors. 